\title{
Information, communication, and cancer patients' trust in the physician: what challenges do we have to face in an era of precision cancer medicine?
}

\author{
Theresia Pichler ${ }^{1,2}$ (1) Amy Rohrmoser ${ }^{3}$ - Anne Letsch ${ }^{3,4} \cdot$ C. Benedikt Westphalen ${ }^{2,5} \cdot$ Ulrich Keilholz $^{3}$. \\ Volker Heinemann $^{2,5}$. Mario Lamping ${ }^{3,4}$. Philipp J. Jost ${ }^{6,7} \cdot$ Kristina Riedmann $^{6,7}$ • Peter Herschbach ${ }^{8}$ • Ute Goerling ${ }^{3}$
}

Received: 12 May 2020 / Accepted: 19 August 2020 / Published online: 3 September 2020

(C) The Author(s) 2020

\begin{abstract}
Purpose Despite promising achievements in precision cancer medicine (PCM), participating patients are still faced with manifold uncertainties, especially regarding a potential treatment benefit of molecular diagnostics (MD). Hence, MD poses considerable challenges for patient information and communication. To meet these challenges, healthcare professionals need to gain deeper insight into patients' subjective experiences. Therefore, this qualitative study examined information aspects of MD programs in cancer patients.

Methods In two German Comprehensive Cancer Centers, 30 cancer patients undergoing MD participated in semi-structured interviews on information transfer and information needs regarding MD. Additionally, patients provided sociodemographic and medical data and indicated their subjective level of information (visual analogue scale, VAS, 0-10).

Results On average patients had high levels of information (mean $=7$, median $=8)$; nevertheless $20 \%(n=6)$ showed an information level below 5 points. Qualitative analysis revealed that patients show limited understanding of the complex background of MD and have uncertainties regarding their personal benefit. Further, patients described unmet information needs. Existential threat in awaiting the results was experienced as burdensome. To withstand the strains of their situation, patients emphasized the importance of trusting their physician.

Conclusion The challenges in PCM consist in providing unambiguous information, especially concerning treatment benefit, and providing guidance and support. Therefore, psycho-oncology needs to develop guidelines for adequate patient communication in order to help healthcare providers and cancer patients to handle these challenges in the developing field of PCM.
\end{abstract}

Keywords Oncology $\cdot$ Whole genome sequencing $\cdot$ Precision cancer medicine $\cdot$ Information $\cdot$ Communication $\cdot$ Molecular diagnostic

Peter Herschbach and Ute Goerling are joint senior authorship.

Electronic supplementary material The online version of this article (https://doi.org/10.1007/s00520-020-05692-7) contains supplementary material, which is available to authorized users.

Theresia Pichler

theresia.pichler@mri.tum.de

1 Comprehensive Cancer Center Munich, partner site TUM, Klinikum rechts der Isar, Munich, Germany

2 Comprehensive Cancer Center Munich, partner site LMU, University hospital, LMU Munich, Munich, Germany

3 Charité - Universitätsmedizin Berlin, Charité Comprehensive Cancer Center, Berlin, Germany
4 Department of Hematology and Oncology, Charité Universitätsmedizin Berlin, Campus Benjamin Franklin, Berlin, Germany

5 Department of Medicine III, University Hospital, LMU Munich, Munich, Germany

6 Center for Personalized Oncology (ZPO), Comprehensive Cancer Center Munich, partner site TUM, Munich, Germany

7 Medical Department III for Hematology and Oncology, Klinikum rechts der Isar, TUM, Munich, Germany

8 Munich, Germany 


\section{Background}

Rapid progress in the development of novel molecular diagnostic (MD) and therapeutic modalities holds great promise to improve cancer care [1, 2]. However, as the field of precision cancer medicine (PCM) is still developing, the interweaving of translational research and clinical practice [3] poses considerable challenges for patient information transfer and communication. With the broad use of comprehensive genomic profiling, PCM has changed the way evidence is generated and how fast new findings are brought into clinical practice [3]. While oncology has historically relied on randomized controlled trials to generate evidence, the complexity of genomics-driven medicine however is only partly addressable in classical clinical trials (the $n=1$, dilemma, [3]). So far, molecularly guided treatment based on comprehensive molecular profiling across all cancers is largely still exploratory and often lacks satisfying evidence $[4,5]$. Even if a genomic alteration is found, only a small percentage of patients gain a substantial treatment benefit from molecularly guided treatment [6-8].

These uncertainties resulting from a lack of evidence are aggravated by missing infrastructure and the clinical characteristics of advanced cancer patients. For patients suffering from advanced stage cancer, maintaining hope in such a vulnerable period of disease seems crucial [9]. As a result, patients show high expectations of a personal treatment benefit [10-12].

Given the manifold uncertainties these patients encounter, questions arise about what information patients need undergoing PCM and how best to communicate it. So far, only a few studies have examined psychosocial implications for patients of PCM programs, and only some of those investigated relevant aspects of information transfer and patient communication in this regard. Many patients have limited understanding of the complex background and/or misinterpret the implications of genomic profiling [13-16]. Over one-third of patients require additional counseling [14]. The review of Wolyniec et al. [17] — analyzing quantitative and qualitative studies on knowledge and information regarding genomic testing - found that in some studies, less than half of patients were able to reflect the procedure and contents of molecular genetic testing. Considering their high expectations, especially regarding a potential treatment benefit [12-14, 18], patients might have difficulties dealing with disappointments. Recent literature emphasizes the need for adequate communication, education, and counseling to ensure informed consent in an era of PCM $[10,11,19,20]$. So far, an in-depth comprehension of patients' perspectives on information about PCM in a representative sample prior to disclosure of results of comprehensive molecular profiling that also shed light on potential distress is still pending. Therefore, the aim of this study was to illustrate patients' subjective needs when undergoing comprehensive genomic profiling and - in this regard - to illuminate potential challenges of communication and information transfer for healthcare providers.

\section{Methods and materials}

\section{Participants and setting}

A qualitative interview study concerning patients' perspectives on molecular diagnostic was conducted at the Comprehensive Cancer Center Munich (CCC Munich) and the Charité Comprehensive Cancer Center in Berlin (CCCC). Eligible were adult, German-speaking cancer patients who consented to undergo extensive molecular diagnostics of tumor material. We recruited patients from PCM programs which were either whole genome sequencing within a research study or panel sequencing including scientific registry but primarily subjected to clinical practice. For all programs, patients gave informed consent after receiving standardized written and verbal information by a physician.

For both programs, inclusion criteria comprised (a) prevalence of a reliable tumor diagnosis, (b) patients' refractory to standard therapy, (c) good general condition $(\mathrm{ECOG} \leq 2)$, (d) advanced tumor disease or rare cancer, and (e) recommendation by organ-specific tumor board or treating oncologist. For whole genome sequencing, the following additional criteria had to be fulfilled: younger than or equal to 50 years of age and a life expectancy of more than 6 months. Additionally, patients included in whole genome sequencing programs could choose whether or not they wanted to be informed about identification of possible cancer predisposition syndromes, if there were indications found in the germline. In case of a significant mutation, patients of both programs were preferentially treated as part of a given clinical trial or - where appropriate - would be treated off label. A standardized informed consent and patient information was provided for patients of both programs. According to experts' ratings, programs were highly comparable. For a detailed description of study methods, see also Rohrmoser et al. [12].

\section{Study procedure and measures}

Data collection took place from November 2017 to December 2018. The interview was accomplished after patients had given informed consent to MD and prior to receiving the results of the analysis. After verbal and written informed consent for the interview study, patients were asked to provide basic sociodemographic and clinical data. Participants were screened for distress using a self-assessment questionnaire. This data has been reported earlier [12] and is not included in the present qualitative evaluation. Furthermore, study assistants explored aspects of information and expectations by 
means of a semi-structured interview guide (supplementary file 1). In addition, patients indicated on a visual analogue scale how well-informed they felt $(0=$ "no information," $10=$ "very good information"). The face-to-face interviews lasted approximately $20 \mathrm{~min}$. Interviews were audio-taped and transcribed literally, and personal information was anonymized. The study was approved by the Ethics Committee of the Technical University of Munich (533/17 S), the Ethics Committee of the University of Munich (17873), and the Ethics Committee of the Charité Universitätsmedizin Berlin (EA1/137/17).

\section{Data analyses}

Transcripts of interviews were organized using MAXQDA, a software for qualitative analysis [21]. Referring to Kuckartz' thematic content analysis [22], we used a deductive-inductive approach. We identified relevant passages pertaining to patients' information regarding MD and its relevance in the current situation of waiting for the results of the MD analysis and grouped it into categories. In doing so, predetermined categories from the interview as well as codes empirically emerging from the data were generated. Code systems were critically reflected and continuously redefined in expert groups within the psychological, medical, and methodological field. IBM SPSS Statistics software package version 25 [23] was used for descriptive analysis.

\section{Results}

\section{Sample characteristics}

Of 33 approached patients, 30 gave informed consent (14 female). Mean age was 46 years $(\mathrm{SD}=11.2$ years, range $=$ 26-77 years). Most patients had metastases (83\%, $n=25)$; illness duration was $28.3(\mathrm{SD}=45.5)$ months on average (range $=0-160$ months; median $=9$ months; for sample details, see Table 1).

\section{Special aspects of information management regarding molecular diagnostics}

Three aspects were identified as particularly characteristic for information and communication regarding the novel molecular research approach (Fig. 1): (a) limited understanding of and limited information about the complex background of PCM, (b) uncertainties regarding personal benefits of PCM, and (c) the central role that the physician played to manage patients' challenging situation while awaiting the results.
Table 1 Sociodemographic and medical characteristics of the study patients $(N=30)$ [12]

\begin{tabular}{|c|c|c|c|}
\hline Patients $n=30$ & Location 1 & Location 2 & Total $(\%)$ \\
\hline \multicolumn{4}{|l|}{ Age } \\
\hline$\leq 50$ years & 12 & 10 & $22(73)$ \\
\hline$>50$ years & 3 & 5 & $8(27)$ \\
\hline \multicolumn{4}{|l|}{ Gender } \\
\hline Male & 8 & 8 & $16(53)$ \\
\hline Female & 7 & 7 & $14(47)$ \\
\hline \multicolumn{4}{|l|}{ Living status } \\
\hline Living alone & 1 & 2 & $3(10)$ \\
\hline Living with partner & 13 & 13 & $26(87)$ \\
\hline Living with relatives & 1 & 0 & $1(3)$ \\
\hline \multicolumn{4}{|l|}{ Education } \\
\hline Elementary school & 2 & 2 & $4(13)$ \\
\hline Junior high & 3 & 7 & $10(33)$ \\
\hline High school & 3 & 0 & $3(10)$ \\
\hline Graduated & 7 & 6 & $13(43)$ \\
\hline \multicolumn{4}{|l|}{ Entity of cancer diagnosis } \\
\hline Gastrointestinal tumor & 3 & 5 & $8(27)$ \\
\hline Urological tumor & 1 & 4 & $5(17)$ \\
\hline Neuroendocrine tumor & 4 & 0 & $4(13)$ \\
\hline Head and neck tumor & 3 & 0 & $3(10)$ \\
\hline Breast tumor & 1 & 1 & $2(7)$ \\
\hline Melanoma & 0 & 2 & $2(7)$ \\
\hline Sarcoma & 2 & 0 & $2(7)$ \\
\hline Gynecological tumor & 0 & 1 & $1(3)$ \\
\hline Lung tumor & 0 & 1 & $1(3)$ \\
\hline Lymphoma & 1 & 0 & $1(3)$ \\
\hline Brain tumor & 0 & 1 & $1(3)$ \\
\hline \multicolumn{4}{|l|}{ Metastases } \\
\hline Yes & 13 & 12 & $25(83)$ \\
\hline No & 2 & 3 & $5(17)$ \\
\hline \multicolumn{4}{|l|}{ Illness duration } \\
\hline Up to 3 months & 3 & 4 & $7(23)$ \\
\hline$>3$ months to 1 year & 5 & 7 & $12(40)$ \\
\hline$>1$ year to 5 year & 4 & 2 & $6(20)$ \\
\hline$>5$ years & 3 & 2 & $5(17)$ \\
\hline \multicolumn{4}{|l|}{ Prior treatments } \\
\hline Surgery & 8 & 6 & $14(47)$ \\
\hline Radiotherapy & 6 & 7 & $13(43)$ \\
\hline Chemotherapy & 10 & 12 & $22(73)$ \\
\hline Immunotherapy & 3 & 3 & $6(20)$ \\
\hline
\end{tabular}

\section{Limited understanding and information of the complex} background of PCM

Results of the visual analogue scale on patients' subjective level of information revealed that on average, patients felt to have a high level of information ( mean $=7$, median $=8, \mathrm{SD}=$ 2 , range $=1.5-10)$; nonetheless $20 \%(n=6)$ indicated an 


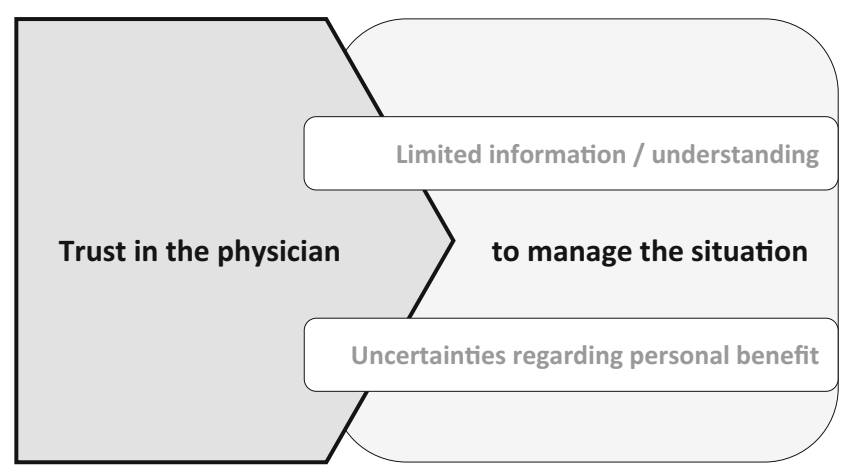

Fig. 1 Information and communication regarding the novel molecular research approach

information level below 5 points. These highly heterogeneous subjective information levels were also found in the qualitative data. Patients indicated that they had a lay understanding of PCM in a way that they understood the basic approach but found the details and background of tumor genomic profiling to be too complex for them to understand. However, patients indicated that these details were not relevant to them.

(...) it was understandable to me. Probably not down to the last detail, but I know now what it's about and how it is analyzed, and so I think it's enough for me. (IP9)

While most patients knew about the organizational process relevant to them, some missed information about the next steps after providing their tumor tissue, if and in what way they would be contacted after results were available and the actual kind of treatment resulting therefrom:

What happens after that? Will I be contacted? Will, uh, will any medication be sent to me? $\mathrm{Uh}, \mathrm{mh}$, how... how, does that work? Do I have to come back here? Is it a... infusion? Is it chemo? Is it...? Well, this...this section is somehow still... not so clear to me. (IP12)

Over the course of the disease, for some patients, their need for information changed in general: While some mentioned that after some time they encouraged themselves to ask more questions about subjective implications of medical information, others described to have learned not to seek further information, because they were concerned that this information would cause them anxiety. Patients described that this change in information needs also to be applied to their information seeking regarding PCM. For example, patients mentioned that they would not go too much into detail, since they already had so many "turnarounds" (M110) that they were "not thinking about anything in advance" (M110) anymore and therefore experienced MD less agitatedly. Figure 2 presents a summary of information needs patients explicitly stated throughout the interview.

\section{Uncertainties regarding personal benefits}

Although in a lot of cases expectations were very high [12], many patients indicated their uncertainty about their actual chance to personally benefit by participating in the program. Some patients were not certain whether they would (merely) contribute to research or if and to what extent they could expect a personal benefit.

Well, I have a basic skepticism to the extent that I say, medically it's all definitely meaningful and valuable, but whether something really ensues in the...for my specific case... let's see. (IP10)

Yes, I'm missing it, uh, I'm actually missing...since I don't know now, if there can still be an advantage for me at my age or maybe in ten years or whatever...in twenty years or something. Somehow...how shall I put it? Some purpose it will have in a way that medicine makes progresses. But whether it's short term or long term, I don't know. (...) Well, no I wasn't actually told, but I guess it would help research and I doubt it's gonna help ME. (IP17)

Many patients experienced this uncertainty as particularly burdensome while awaiting the results of the program.

So yes, and as I said, chemotherapy...is getting harder and harder to endure. So, at the moment the time factor is very...it is an important ....an issue since yesterday, right? (...) I can stand that [the waiting period] with chemotherapy, but...they [these months] will be exhausting. That is clear. I know that. (IP7)

This waiting time. Waiting, waiting, waiting. That is always the worst. That is ALWAYS the worst. (IP27)

Another patient described her perception while waiting for concrete results of PCM as "hanging in the balance":

My son corresponded back and forth with Dr. A., and he was also always nice and positive, but he probably can't say anything very concrete like that until this biopsy in [city 1]... we're all pending there like everything is still hanging in the balance. (IP19)

\section{Trust in the physician}

Overall it became clear that throughout the course of the program, the trust in the physician played a central role for many patients participating in PCM. Regarding the reasons for participating in the program, one patient noted: 


\section{Communication and information needs of patients participating in Precision Cancer Medicine}

- Simple and comprehensible language (in the informed consent form and during medical consultation)

- Transparent and engaging information about the procedure of MD programs (workflow), e.g. information about date and way patients will receive feedback

- Information about the expected benefits of participation and treatment options

- Information regarding heredity for one's children / relatives

- Information that is oriented on patients' current subjective preferences

- Instance, where they can address questions

- Further sources of validated information if needed (for patients themselves and their dependents; e.g. information sheets, information on the hospitals homepage etc.)

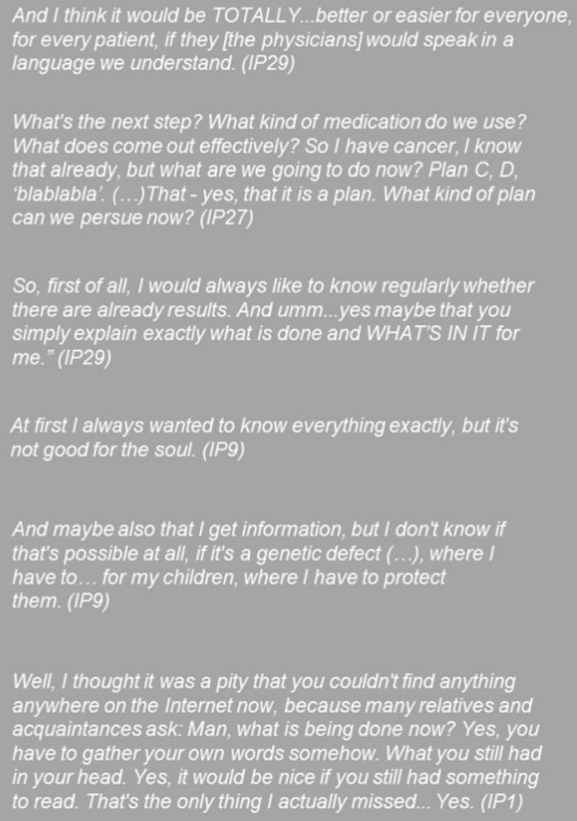

Fig. 2 Summary of information needs patients explicitly stated throughout the interview

Well, that has a lot to do with trust, of course that is - for the patient it is the most important thing that you have trust in your doctor. There needs to be good chemistry, I can only speak for myself now, but I am sure that others feel the same...very important. (IP29)

Some mentioned that due to participating in the program, they finally had found a main contact person for their needs. Others pointed out that they had the feeling that the doctor "really cares about it and wants to do it [the PCM]" (IP9). Another patient stated that he liked the "feeling that the doctor is actually dealing with it [her case]" (IP4).

In many cases, it seemed that having the opportunity to participate in a novel research approach strongly influenced the trust in the treating oncologist:

So, I talked to Dr. B. too. And he also said to me: 'Yes, we would do the same as the [hospital 1] doctors did. But there's another study, there are also other things we can do.' And I think that's what I missed [at hospital 1]. I'm somehow patient $\mathrm{X}$ there and here I have the feeling with Mr. B., that's such a challenge, right? We want to defeat the cancer now or have it under control and that I feel comfortable here somehow. (IP13)

In that regard, faith in research was evident in numerous interviews:
Well, I informed myself that there are really specialists there who are also investigating this in [City 1]. (...). And uh, they really are the absolute specialists and I hope they will find out what makes my therapy so ugh, so, as they say, so complicated, right? (IP14)

Furthermore, the trust in the physician seemed to "buffer" missing or incomprehensible information as well as uncertainty about any personal benefit.

(...) So far, I've understood everything I can imagine, how it should work, and the rest is uninteresting for me now, because I trust in the doctors, I have to say. (IP21)

It seemed that information exchange with the oncologist helped some patients deal with difficult feelings while awaiting the results of the PCM.

That always depends: If you don't feel well, then you wish you could get information right now and immediately (laughs.). If things are good for you, then you don't want to hear anything (laughs.) (...) because then simply this normality prevails again. So that's not the case if you're feeling bad, then you want the doctor to call you every hour and ask you how you're feeling. But if you are well, then not, then all that is gone. (IP29) 
And Dr. C., I don't know how many times she said that if I have questions, I can always ask her. So... I feel completely comfortable ...ugh...informed (*patient laughs*). (IP2)

\section{Discussion}

Although patients felt well informed on average, many had to deal with a lack of PCM understanding. This has also been found in previous work [13]. A small number of patients had misinterpretations or questions regarding heredity and treatment options in case of a positive mutation result. In line with previous work on genomic counseling [24, 25], the findings of this study suggest that for patients participating in this complex program, it is enough to have a generic understanding of PCM, provided in a simple, comprehensible language. In addition, especially information concerning the overall process (e.g., time point of result disclosure) is important to provide orientation for the patients. According to patients' need of transparent, continuous, and validated information and a defined medical contact, this study emphasizes the importance of providing appropriate infrastructure with validated information, e.g., by a PCM consultation hour. Moreover, misinterpretations and distress might be prevented if physicians anticipate "hot topics" — such as heredity — and address these with the patient in advance. In this regard, Goerling et al. [26] showed the bidirectional relationship between satisfaction with information and symptoms of anxiety.

Patients described the uncertainty while awaiting the results of the sequencing as burdensome, bearing in mind that most of the interviewed patients suffered from advanced disease and were exhausted from previous treatment. Overall, the existential threat seemed to be prominent apart from specific distress arising by participating in a PCM program.

In view of this, it seemed that patients' trust in the physician buffered the psychological strain caused by the difficulties they experienced. This finding appears to be well substantiated by Shenolikar et al. [27] who found that a heightened vulnerability may increase trust in the physician. For some patients, the buffering effect of trust in their physicians was further underlined by a "faith in science". In this regard, literature shows that beside a sense of caring and contextual factors (such as length of consultation), patients' trust in their physician is mainly contingent by communicative aspects, competence, and honesty [28-32]. Furthermore, Atherton et al. [33] found that patients feel content with the information received when it is built on a caring relationship with their physician.

Although most patients expected a treatment benefit and thus obviously consented to participate (see also [12]), many seemed unaware of the small chances of an actual personal benefit. Here, it is paramount for oncologists to openly and empathetically discuss hopes and expectations as well as actual chances of a benefit from comprehensive genomic profiling with the patient. Furthermore, it seems crucial to strengthen physicians' confidence in their genomic knowledge, as this was found to be not sufficient in other studies [34]. Additionally, in our view, it seems vital that patients get an idea about the complex interweaving of research and clinical practice. This should reduce misconceptions and enhance informed consent.

This study investigated patients' perceptions on information regarding precision oncology programs. The manifold uncertainties arising from the evolving research approach of PCM are considerable for patient information and communication. Major challenges in PCM are to offer patients comprehensible information and guidance while supporting them to manage this vulnerable period of disease. This can be ensured by providing a continuous information transfer as well as transparent and standardized procedures. A communication based on a trusting relationship with the physician, which is built on competence and care, might offer a secure and reassuring counterpart against the uncertainties discussed. Moreover, information about the (for most cases) exploratory nature of PCM and the corresponding likelihood for a personal benefit needs to be openly and empathetically discussed, tailored to a patient's current situation. Besides providing psycho-oncological support, we recommend the development of guidelines to help healthcare providers handle these challenges of patient communication in the growing field of PCM.

\section{Limitations}

The findings' generalizability is limited by the qualitative study design with the small sample size. Furthermore, the mean age of study participants was younger, and education level was higher compared with other studies [14], and thus, results may not be applicable for other patient populations. We recruited patients from different PCM approaches; however, the programs were rated as highly comparable by experts. The results gained were derived from qualitative interviews which explored patients' subjective perception; no information material nor the informed consent talk has been analyzed to verify patients' quotes.

Code availability MAXQDA, Software for qualitative data analysis, 1989-2019, VERBI Software. Consult. Social research GmbH, Berlin, Germany.

Authors' contributions All authors contributed to the study conception and design. Data collection and analysis were performed by Amy Rohrmoser, Ute Goerling, Peter Herschbach, and Theresia Pichler. The first draft of the manuscript was written by Theresia Pichler, and all authors commented on previous versions of the manuscript. All authors read and approved the final manuscript. 
Funding Open Access funding provided by Projekt DEAL.

Data availability The datasets generated during and/or analyzed during the current study are available from the corresponding author on reasonable request.

\section{Compliance with ethical standards}

Conflict of interest Outside of the submitted work, PD Dr. Letsch reports personal fees from Bristol Myers Squibb, MSD (Merck \& Co), Bayer AG, AstraZeneca, Roche, Pfizer, Tesaro, Sanofi, Incyte, and Merck KGaA. Dr. Westphalen reports grants from Roche and personal fees and other from Bayer, Celgene, Ipsen, Rafael, RedHill, Roche, Servier, Shire/Baxalta, and Taiho, outside the submitted work. Prof. Keilholz reports grants and personal fees from AstraZeneca, Pfizer, Bayer, and Merck and personal fees from BMS, MSD, and Novartis, outside the submitted work. Prof. Dr. Heinemann reports grants, personal fees, and non-financial support from Merck, Amgen, Roche, and SIRTEX; grants and personal fees from Sanofi and Shire; personal fees and non-financial support from Servier and BMS; MSD grants from Pfizer, Celgene, and Boehringer-Ingelheim; personal fees from Halozyme and Pierre-Fabre; and non-financial support from Bayer, outside the submitted work. Prof. Dr. Jost has had a consulting or advisory role and received honoraria, research funding, and/or travel/accommodation expenses from AbbVie, BMS, Boehringer, Novartis, Pfizer, Servier, and Celgene, outside the submitted work. Dr. Riedmann reports personal fees from Bayer Vital GmbH, outside the submitted work. Dr. Goerling reports personal fees from German Cancer Aid, Federal Ministry of Education and Research, outside the submitted work. All the other authors disclose no potential conflicts of interest.

Research involving human participants/ethics approval All procedures performed in studies involving human participants were in accordance with the ethical standards of the institutional and/or national research committee and with the 1964 Helsinki declaration and its later amendments or comparable ethical standards. The study was approved by the Ethics Committee of the Technical University of Munich (533/17 S), the Ethics Committee of the University of Munich (17-873), and the Ethics Committee of the Charité - Universitätsmedizin Berlin (EA1/137/17). The study received positive data protection votes from the responsible committees (Munich: verification by data protection official; Berlin: 473/ 17/ST3).

Informed consent All patients completed an informed consent form.

Consent to participate Informed consent was obtained from all individual participants included in the study.

Consent to publish Patients signed informed consent regarding publishing their data.

Open Access This article is licensed under a Creative Commons Attribution 4.0 International License, which permits use, sharing, adaptation, distribution and reproduction in any medium or format, as long as you give appropriate credit to the original author(s) and the source, provide a link to the Creative Commons licence, and indicate if changes were made. The images or other third party material in this article are included in the article's Creative Commons licence, unless indicated otherwise in a credit line to the material. If material is not included in the article's Creative Commons licence and your intended use is not permitted by statutory regulation or exceeds the permitted use, you will need to obtain permission directly from the copyright holder. To view a copy of this licence, visit http://creativecommons.org/licenses/by/4.0/.

\section{References}

1. Horak P, Frohling S, Glimm H (2016) Integrating next-generation sequencing into clinical oncology: strategies, promises and pitfalls. ESMO Open 1(5):e000094. https://doi.org/10.1136/esmoopen2016-000094

2. Holch JW, Metzeler KH, Jung A, Riedmann K, Jost PJ, Weichert W, Kirchner T, Heinemann V, Westphalen CB (2017) Universal genomic testing: the next step in oncological decision-making or a dead end street? Eur J Cancer 82:72-79. https://doi.org/10.1016/j. ejca.2017.05.034

3. Marchiano EJ, Birkeland AC, Swiecicki PL, Spector-Bagdady K, Shuman AG (2018) Revisiting expectations in an era of precision oncology. Oncologist 23(3):386-388. https://doi.org/10.1634/ theoncologist.2017-0269

4. Salgado R, Moore H, Martens JWM, Lively T, Malik S, McDermott U, Michiels S, Moscow JA, Tejpar S, McKee T, Lacombe D, Faculty I (2018) Steps forward for cancer precision medicine. Nat Rev Drug Discov 17(1):1-2. https://doi.org/10. 1038/nrd.2017.218

5. Moscow JA, Fojo T, Schilsky RL (2018) The evidence framework for precision cancer medicine. Nat Rev Clin Oncol 15(3):183-192

6. Massard C, Michiels S, Ferte C, Le Deley MC, Lacroix L, Hollebecque A, Verlingue L, Ileana E, Rosellini S, Ammari S, Ngo-Camus M, Bahleda R, Gazzah A, Varga A, Postel-Vinay S, Loriot Y, Even C, Breuskin I, Auger N, Job B, De Baere T, Deschamps F, Vielh P, Scoazec JY, Lazar V, Richon C, Ribrag V, Deutsch E, Angevin E, Vassal G, Eggermont A, Andre F, Soria JC (2017) High-throughput genomics and clinical outcome in hardto-treat advanced cancers: results of the MOSCATO 01 trial. Cancer Discov 7(6):586-595. https://doi.org/10.1158/2159-8290. CD-16-1396

7. Meric-Bernstam F, Brusco L, Shaw K, Horombe C, Kopetz S, Davies MA, Routbort M, Piha-Paul SA, Janku F, Ueno N, Hong D, De Groot J, Ravi V, Li Y, Luthra R, Patel K, Broaddus R, Mendelsohn J, Mills GB (2015) Feasibility of large-scale genomic testing to facilitate enrollment onto genomically matched clinical trials. J Clin Oncol 33(25):2753-2762. https://doi.org/10.1200/ JCO.2014.60.4165

8. Stockley TL, Oza AM, Berman HK, Leighl NB, Knox JJ, Shepherd FA, Chen EX, Krzyzanowska MK, Dhani N, Joshua AM, Tsao MS, Serra S, Clarke B, Roehrl MH, Zhang T, Sukhai MA, Califaretti N, Trinkaus M, Shaw P, van der Kwast T, Wang L, Virtanen C, Kim RH, Razak AR, Hansen AR, Yu C, Pugh TJ, Kamel-Reid S, Siu LL, Bedard PL (2016) Molecular profiling of advanced solid tumors and patient outcomes with genotypematched clinical trials: the Princess Margaret IMPACT/ COMPACT trial. Genome Med 8(1):109. https://doi.org/10.1186/ s13073-016-0364-2

9. Marron JM, Quach E, Pikman Y, Janeway KA, Mack JW, Consortium G, Investigators LC (2019) Participant hopes and expectations regarding outcomes of genomic sequencing research in pediatric oncology. Journal of Clinical Oncology - published online before print 37(15_suppl):10020. https://doi.org/10.1200/JCO. 2019.37.15_suppl.10020

10. Marron JM, DuBois SG, Glade Bender J, Kim A, Crompton BD, Meyer SC, Janeway KA, Mack JW (2016) Patient/parent perspectives on genomic tumor profiling of pediatric solid tumors: the individualized cancer therapy (iCat) experience. Pediatr Blood Cancer 63(11):1974-1982. https://doi.org/10.1002/pbc.26137

11. Miller FA, Hayeems RZ, Bytautas JP, Bedard PL, Ernst S, Hirte H, Hotte S, Oza A, Razak A, Welch S, Winquist E, Dancey J, Siu LL (2014) Testing personalized medicine: patient and physician expectations of next-generation genomic sequencing in late-stage cancer 
care. Eur J Hum Genet 22(3):391-395. https://doi.org/10.1038/ ejhg.2013.158

12. Rohrmoser A, Pichler T, Letsch A, Westphalen CB, Keilholz U, Heinemann V, Goerling U, Herschbach P (2020) Cancer patients' expectations undergoing extensive molecular diagnostics - a qualitative study. Psycho-Oncology. 29(2):423-429. https://doi.org/10. 1002/pon.5282

13. Best MC, Bartley N, Jacobs C, Juraskova I, Goldstein D, Newson AJ, Savard J, Meiser B, Ballinger M, Napier C, Thomas D, Biesecker B, Butow P, Members of the PiGeOn P (2019) Patient perspectives on molecular tumor profiling: "why wouldn't you?". BMC Cancer 19(1):753. https://doi.org/10.1186/s12885-019-5920$\mathrm{x}$

14. Blanchette PS, Spreafico A, Miller FA, Chan K, Bytautas J, Kang S, Bedard PL, Eisen A, Potanina L, Holland J, Kamel-Reid S, McPherson JD, Razak AR, Siu LL (2014) Genomic testing in cancer: patient knowledge, attitudes, and expectations. Cancer 120(19): 3066-3073. https://doi.org/10.1002/cncr.28807

15. Gray SW, Hicks-Courant K, Lathan CS, Garraway L, Park ER, Weeks JC (2012) Attitudes of patients with cancer about personalized medicine and somatic genetic testing. J Oncol Pract 8(6):329 335, 322p following 335. https://doi.org/10.1200/JOP.2012. 000626

16. Liang R, Meiser B, Smith S, Kasparian NA, Lewis CR, Chin M, Long GV, Ward R, Menzies AM, Harris-Wai JN, Kaur R (2017) Advanced cancer patients' attitudes towards, and experiences with, screening for somatic mutations in tumours: a qualitative study. Eur J Cancer Care (Engl) 26(6):e12600. https://doi.org/10.1111/ecc. 12600

17. Wolyniec K, Sharp J, Lazarakis S, Mileshkin L, Schofield P (2020) Understanding and information needs of cancer patients regarding treatment-focused genomic testing: a systematic review. Psychooncology 29(4):632-638. https://doi.org/10.1002/pon.5351

18. Roberts JS, Gornick MC, Le LQ, Bartnik NJ, Zikmund-Fisher BJ, Chinnaiyan AM, team M-OS (2019) Next-generation sequencing in precision oncology: patient understanding and expectations. Cancer Med 8(1):227-237. https://doi.org/10.1002/cam4.1947

19. Maughan T (2017) The promise and the hype of 'personalised medicine'. New Bioeth 23(1):13-20. https://doi.org/10.1080/ 20502877.2017.1314886

20. Yanes T, Willis AM, Meiser B, Tucker KM, Best M (2019) Psychosocial and behavioral outcomes of genomic testing in cancer: a systematic review. Eur J Hum Genet 27(1):28-35. https://doi. org/10.1038/s41431-018-0257-5

21. MAXQDA (1989-2019) Software for qualitative data analysis.1989-2019, VERBI software. Consult. Social research GmbH, Berlin

22. Kuckartz U (2016) Qualitative Inhaltsanalyse. Methoden, Praxis, Computerunterstützung (Grundlagentexte Methoden, 3., überarbeitete Auflage). Beltz Juventa, Weinheim
23. Ibm C (2017) IBM SPSS statistics for windows, version Q3 25.0. IBM Corp, Armonk

24. Ayuso C, Millan JM, Mancheno M, Dal-Re R (2013) Informed consent for whole-genome sequencing studies in the clinical setting. Proposed recommendations on essential content and process. Eur J Hum Genet 21(10):1054-1059. https://doi.org/10.1038/ejhg. 2012.297

25. Biesecker B, Austin J, Caleshu C (2017) Theories for psychotherapeutic genetic counseling: fuzzy trace theory and cognitive behavior theory. J Genet Couns 26(2):322-330. https://doi.org/10.1007/ s10897-016-0023-1

26. Goerling U, Faller H, Hornemann B, Honig K, Bergelt C, Maatouk I, Stein B, Teufel M, Erim Y, Geiser F, Niecke A, Senf B, Wickert M, Buttner-Teleaga A, Weis J (2020) Information needs in cancer patients across the disease trajectory. A prospective study. Patient Educ Couns 103(1):120-126. https://doi.org/10.1016/j.pec.2019. 08.011

27. Shenolikar RA, Balkrishnan R, Hall MA (2004) How patientphysician encounters in critical medical situations affect trust: results of a national survey. BMC Health Serv Res 4(1):24. https:// doi.org/10.1186/1472-6963-4-24

28. Thom DH (2001) Physician behaviors that predict patient trust. J Fam Pract 50(4):323-328

29. Fiscella K, Meldrum S, Franks P, Shields CG, Duberstein P, McDaniel SH, Epstein RM (2004) Patient trust: is it related to patient-centered behavior of primary care physicians? Med Care 42(11):1049-1055

30. Haas JS, Phillips KA, Baker LC, Sonneborn D, McCulloch CE (2003) Is the prevalence of gatekeeping in a community associated with individual trust in medical care? Med Care 41(5):660-668

31. Hagerty RG, Butow PN, Ellis PM, Lobb EA, Pendlebury SC, Leighl N, MacLeod C, Tattersall MH (2005) Communicating with realism and hope: incurable cancer patients' views on the disclosure of prognosis. J Clin Oncol 23(6):1278-1288. https://doi.org/10. 1200/JCO.2005.11.138

32. Hillen MA, de Haes HC, Smets EM (2011) Cancer patients' trust in their physician-a review. Psychooncology 20(3):227-241. https:// doi.org/10.1002/pon.1745

33. Atherton K, Young B, Salmon P (2017) Understanding the information needs of people with haematological cancers. A metaethnography of quantitative and qualitative research. Eur J Cancer Care (Engl) 26(6). https://doi.org/10.1111/ecc.12647

34. Gray SW, Hicks-Courant K, Cronin A, Rollins BJ, Weeks JC (2014) Physicians' attitudes about multiplex tumor genomic testing. J Clin Oncol 32(13):1317-1323. https://doi.org/10.1200/JCO. 2013.52.4298

Publisher's note Springer Nature remains neutral with regard to jurisdictional claims in published maps and institutional affiliations. 